\title{
Quality of Life in Urologic Cancer Patients: Importance of and Satisfaction With Specific Quality of Life Domains
}

\author{
Katja Leuteritz \\ Department of Medical Psychology and Medical Sociology, University of Leipzig \\ Diana Richter \\ Department of Medical Psychology and Medical Sociology, University of Leipzig \\ Anja Mehnert-Theuerkauf \\ Department of Medical Psychology and Medical Sociology, University of Leipzig \\ Jens-Uwe Stolzenburg \\ Department of Urology, University of Leipzig \\ Andreas Hinz ( $\nabla$ andreas.hinz@medizin.uni-leipzig.de ) \\ University of Leipzig https://orcid.org/0000-0002-6986-8145
}

\section{Research Article}

Keywords: Quality of life, Urology, Prostate cancer, Satisfaction, Importance, Health

Posted Date: March 6th, 2021

DOI: https://doi.org/10.21203/rs.3.rs-277215/v1

License: (c) (i) This work is licensed under a Creative Commons Attribution 4.0 International License. Read Full License

Version of Record: A version of this preprint was published at Quality of Life Research on July 18th, 2021. See the published version at https://doi.org/10.1007/s11136-021-02954-7. 


\section{Abstract}

Purpose

Quality of life (QoL) has been the subject of increasing interest in oncology. Most examinations of QoL have focused on health-related QoL while other factors often remain unconsidered. Moreover, QoL questionnaires implicitly assume that the subjective importance of the various QoL domains is identical from one patient to the next. The aim of this study was to analyze QoL in a broader sense, considering the subjective importance of the QoL components.

Methods

A sample of 173 male urologic patients was surveyed twice: once while hospitalized (t1) and once again three months later (t2). Patients completed the Questions on Life Satisfaction questionnaire (FLZ-M), which includes satisfaction and importance ratings for eight dimensions of QoL. A control group was taken from the general population $(n=477)$.

Results

Health was the most important QoL dimension for both the patient and the general population groups. While satisfaction with health was low in the patient group, the satisfaction ratings of the other seven domains were higher in the patient group than in the general population. The satisfaction with the domain partnership/sexuality showed a significant decline from $\mathrm{t} 1$ to $\mathrm{t} 2$. Multiple regression analyses showed that the domains health and income contributed most strongly to the global QoL score at t2 in the patient group.

Conclusions

Health is not the only relevant category when assessing QoL in cancer patients; social relationships and finances are pertinent as well. Importance ratings contribute to a better understanding of the relevance of the QoL dimensions for the patients.

\section{Introduction}

Prostate cancer is the most frequently diagnosed cancer among men, with about 1.3 million new cases being diagnosed annually worldwide [1]. The 5-year survival rate for prostate cancer is relatively high, about $83 \%$ in Europe [2]. Quality of life (QoL) has become an important quality and decision criterion for cancer patients, medical practitioners, and the healthcare system. Multiple studies have been performed to investigate QoL [3-6] and mental health [7-9] in urologic cancer patients and survivors. Most studies found that, compared with other cancer types, QoL among prostate cancer patients was relatively good $[10,11]$. When compared with controls from the general population, prostate cancer survivors often rate global QoL dimensions similarly [12-14]. However, when specific symptoms are considered such as urinary incontinence, bowel or rectal function, or sexual function, prostate cancer patients report significant detriments $[15,16]$.

Studies on QoL among cancer patients have historically focused mainly on health-related QoL [3, 17]. However, QoL is a broader concept that also includes factors such as professional life, leisure activities, and finances. Factors like these need to be considered as well when evaluating cancer patients' QoL and developing supportive measures.

While QoL assessment instruments generally cover several domains, they do not consider the subjective importance of these domains to the individual respondents. It is implicitly assumed that each dimension has roughly the same meaning for each study participant. This however is not necessarily the case. Therefore, attempts have been made to assess the subjective importance of the QoL components and to weight those components with the corresponding importance ratings since important QoL domains correlate more strongly with overall QoL than unimportant ones do [18]. When this more complicated procedure was used the results were generally very similar to the results of the unweighted calculations 
[18-20]. However, the subjective importance of QoL domain is interesting in and of itself, not only as a possible weight factor. Which areas of life become more relevant and which become less relevant after a cancer diagnosis or treatment? Does the importance of health increase, and does the importance of the other dimensions decrease in the perception of cancer patients? Knowledge about this topic is very limited.

One QoL assessment instrument that includes the subjectively attributed importance of the QoL dimensions is the Fragebogen zur Lebenszufriedenheit (Questions on Life Satisfaction) FLZ-M [21]. This questionnaire is therefore suited to answer the questions raised above. A normative study had been performed that allows us to compare the cancer patients' importance and satisfaction assessments with those of the general population. Since importance and satisfaction can change over time in cancer patients, we performed a study with two measurement points spaced three months apart to investigate changes in these variables.

While one way to assess the importance of a life domain is to ask the participants directly to assess the importance they attribute to it, a second approach is to calculate the associations between the specific life domains and a global assessment of QoL. Direct importance ratings of QoL domains can differ from the associations between the satisfaction with these domains and global QoL. While the domains health and family received the highest mean importance ratings in a large general population study [22], the contribution of the domain finances to the variance explanation of global life satisfaction was higher than the contributions of health and friends. We intend to test whether such relationships between direct importance ratings and regression coefficients for the prognosis of global QoL can also be found in cancer patients.

The aims of this study were (a) to analyze satisfaction with and the subjective importance of QoL components in urologic cancer patients in comparison with the general population, (b) to investigate changes in QoL in the patient sample, and (c) to investigate the degree to which the QoL domains predict overall QoL using regression analyses.

\section{Methods}

\section{Patient sample}

Patients were enrolled between June 2015 and February 2017. Men with urologic cancer receiving treatment in a German university hospital were eligible. Study inclusion criteria were: histologically proven urologic carcinoma, age at diagnosis $\geq 18$ years, and being able to read and understand the German language. The patients were surveyed at two time points: once during their hospital stay ( $\mathrm{t} 1$ ) and again three months following hospital release ( $\mathrm{t} 2)$. Most of the patients completed the 11 questionnaire about two days before hospital discharge. For the $t 2$ measurement, the patients received a letter that included the 2 questionnaire with the same instruments and a pre-stamped envelope. Patients who did not respond to the t2 letter were given one reminder. The study received research ethics committee approval from the ethics board of the Medical Faculty of the University of Leipzig. Informed consent was obtained from all of the participants prior to their inclusion in the study.

\section{General population sample}

To compare the results of the cancer patients with those of the general population, we used general population data based on a representative sample $(n=5036)$ of the general German population [23]. The mean age of the cancer patient sample was 63.0 years $(S D=9.5)$. We selected a subsample of males from the general population sample with a comparable mean age of 62.4 years $(S D=12.9)$ and a similar distribution of the education levels according to Table 1 , resulting in a subsample of 477 males. This general population study was also approved by the ethics board of the Medical Faculty of the University of Leipzig.

\section{Instruments}


Several sociodemographic characteristics (age, relationship status, education) were assessed via self-declaration, and medical characteristics (cancer diagnosis, UICC stage, treatment, time since diagnosis) were taken from the clinical patient records.

\section{Questions on Life Satisfaction (FLZ-M)}

QoL was measured with the Questions on Life Satisfaction (FLZ-M) [21] at t1 and at t2. This instrument evaluates the respondent's subjective QoL. It has been used in several medical fields such as cancer [24-26], orthopedics [27], and psychiatry [28]. The questionnaire covers eight areas of life that are assumed to be relevant for most people in the Western world: (1) Friends/Acquaintances; (2) Leisure activities/Hobbies; (3) Health; (4) Income/Financial security, (5) Work/Profession; (6) Housing situation; (7) Family life/Children; and (8) Partnership/Sexuality. The respondents are asked to rate how important each of these areas is and how satisfied they have been with that area over the previous four weeks. The subjects rate the importance of and their satisfaction with the domains on a 5-point Likert scale (range 1-5), whereby higher scores indicate higher levels of importance and satisfaction. Norm values are available [23].

\section{EORTC QLQ-C30}

The participants also completed the EORTC QLQ-C30 [29]. This QoL questionnaire consists of 30 items and includes five functioning scales, nine symptom scales, and a two-item global health/QoL scale. One of the two items of this subscale asks the respondents to rate their QoL on a scale of $1=$ very poor to 7=excellent. We preferred using this single item over the two-item global health/QoL scale because that scale has a focus on the health domain, an area we did not want to favor over the others in this study.

\section{Statistical analysis}

Group differences between patients and the general population were tested using t-tests for unpaired groups; and mean score changes in the patient group were tested with paired t-tests.

Effect sizes $d$ were calculated according to Cohen [30] to indicate the mean score difference between the groups, adjusted for the pooled standard deviation. The association between the satisfaction ratings for the QoL domains (at t 1 ) and global QoL (EORTC QLQ-30 item of global QoL at t2) was analyzed with multiple regression analyses. Two models were calculated. Model M1 included the covariables age, education, and tumor stage, and Model M2 used these three covariables in addition to the baseline value ( $\mathrm{t} 1)$ of $\mathrm{QoL}$ as the independent variables. All analyses used Method $=$ Enter. Statistics were performed with SPSS version 24.

\section{Results}

\section{Sample characteristics}

A total of 212 patients treated for urogenital cancer at a German university hospital were eligible for this study. Of these, 197 (response rate: 93\%) completed the 11 questionnaires and received the t2 questionnaire three months later. With a dropout/failure rate between baseline and follow-up of $12 \%$ (24 patients), a total of 173 complete data sets ( $88 \%$ of the t1 respondents) could be analyzed after the 3-month follow-up measurement. On average, the patients were aged 63.0 years $(\mathrm{SD}=9.5)$ at $\mathrm{t}$ ( (Table 1). Most patients were surveyed within a week of being diagnosed. The most frequent diagnosis was prostate cancer $(n=150 ; 86.7 \%)$. Further characteristics of the sample are given in Table 1 .

The selected sample of the general population was aged 62.4 years (SD = 12.9). Of them, $66(13.8 \%)$ attended school < 10 years, 175 (36.7\%) for 10-11 years, and 236 (49.5\%) for at least 12 years.

Importance of and satisfaction with life domains for patients and the general population 
Importance and satisfaction mean scores of the life domains are given in Tables 2 and 3. Concerning the importance of the domains, the patients rated health and family life/children most highly (Table 2). There was a slight but statistically significant reduction from t1 to $\mathrm{t} 2$ in the importance rating of partnership/sexuality $(d=-0.177 ; p=.018)$. When compared with the general population, the patients ( $\mathrm{t} 1$ ) attributed significantly more importance to four of the eight domains (friends, leisure time, family life, and partnership), and less importance to income. The importance of health was rated nearly equally by both samples.

The life domains the patients reported having the highest satisfaction (Table 3) with were housing and family life, while health and partnership received the lowest scores. Significant changes in satisfaction from t1 to t2 were found in five of the eight domains. Satisfaction increased significantly in the health dimension $(d=0.168 ; \mathrm{p}=0.022)$ and decreased significantly in four domains: partnership $(d=-0.412)$, leisure time $(d=-0.314)$, work $(d=-0.235)$, and family life $(d=$ -0.165). When compared with the general population, the patients' satisfaction ratings (at $t 1)$ were higher in all of the dimensions except health.

\section{Factors associated with global life satisfaction}

The potential of the eight QoL dimensions for predicting general QoL at t2 is analyzed in Table 4. Two models are considered, separately for each dimension. Model 1 includes the satisfaction rating of the domain at $t 1$, together with three covariables: age, education, and tumor stage, as predictors of global QoL at t2. In model 2, the baseline score of QoL is added as a predictor. Concerning model 1 , seven of the eight domains contribute significantly to QoL at t2, the only exception is the domain partnership. The highest beta score was found for the dimension health (beta $=0.418$ ), followed by income (beta $=0.386$ ). When the QoL baseline value is included in the regression (model 2), the beta coefficients of the eight domains become smaller, but still remain statistically significant for five dimensions (friends, health, income, work, and housing). Health has the greatest impact on QoL at t2 (beta $=0.323$ ) even after controlling for baseline QoL. Of the covariables, only tumor stage was statistically significant in all of the analyses, while the impact of age and education was small and insignificant in most cases.

\section{Discussion}

While the impact of urologic cancer on health-related QoL has been examined in multiple studies, the aim of the work presented here was to test whether other QoL domains are also affected by the disease and whether the subjective importance ratings of various QoL dimensions differ between urologic cancer patients and the general population. Health is one of several QoL dimensions included in our analyses; this allows us to investigate the relevance of health in relation to other areas of QoL.

The most relevant QoL dimensions were health and family life, each of which had mean importance scores above 4 on a scale of 1-5. However, the general population also considers health to be the most important dimension; there were no significant differences in the health importance assessments between the patients and the general population. Other general population studies have also reported health receiving the highest importance ratings [19, 31]. While the patients' mean importance ratings were higher than those of the general population in four of the seven other dimensions, the other three dimensions showed an opposite trend. This means that the non-health domains do not become less relevant for people after they have been diagnosed with cancer. As such, it is important to consider problems concerning finances, work, and social relationships when studying patient QoL, as these less physical aspects of life appear to be highly relevant for patients as well [32].

Concerning satisfaction, it is not surprising that the most relevant difference between the patients and the general population was found for the health domain. Nevertheless, the patients' mean satisfaction rating was 3.08 which is nearly exactly the middle of the 1-5 scale, rather than in the lower half of the scale as one might expect. The patients' 
satisfaction ratings were higher than those of the general populations in all of the other domains, and in five of the seven cases even with statistically significant differences. This could be a result of a judgment effect: when there are severe detriments in one area (health in this case), the problems in other areas seem to become less relevant. To gain a better understanding of a person's satisfaction with their health state, it might be useful to consider not only their satisfaction with their health alone but also with their health in relation to their general satisfaction with other areas as well.

During the 3-month period between $\mathrm{t} 1$ and $\mathrm{t} 2$, satisfaction scores slightly improved in the health domain (effect size $d=$ $0.17)$, but became worse in the partnership domain, with a large effect size of $d=-0.41$. The item includes both partnership and sexuality. While in most cases the combination of partnership and sexuality in one dimension makes sense, for prostate cancer patients, these sub-domains can be experienced quite differently. Several patients reported for example that they were highly satisfied with their partnership but very dissatisfied with their sexuality. Since urologic cancer patients often experience urinary and sexual symptoms that do not disappear within the first months after surgery $[12,15,33,34]$ the loss in satisfaction with the combined partnership/sexuality dimension is understandable. Partnership and sexuality are areas of life that deserve special attention in the treatment of urologic cancer patients and survivorship care plans [15, 35-38]. A US-American study showed poorer quality of sexual communication and more sexual dissatisfaction after treatment in patients than in the general population [39]. Moreover, patients' relationship satisfaction, quality of communication about sexuality, and sexual satisfaction were strongly associated with their partner's satisfaction with the overall treatment outcome [15] and partners' level of depression and sexual activity [39].

When considering the changes in QoL scores from $\mathrm{t} 1$ to $\mathrm{t} 2$, one must take into account that they might have been affected by response shift processes whereby the respondents' frames of reference changed due to adaptation processes [40-42]. A study with prostate cancer patients [41] tried to quantify this effect and to estimate "true" changes. So-called thentests [43] could be used to further explain such effects and to better understand the real changes.

How do the eight QoL dimensions contribute to global QoL scores at t2? The results of the regression analyses (Model 1) show that all of the dimensions positively contribute to this global score, and that the only non-significant dimension is partnership. The highest contributions came from the dimensions health (beta $=0.418$ ) and income (beta $=0.386)$. Even after including the baseline value in the regression analyses (model 2), the domains with the highest beta values were health (beta $=0.323$ ) and income (beta $=0.311$ ). A general population study [22] found that income was the strongest predictor of general life satisfaction $(r=.59)$, while health was a weaker predictor $(r=.46)$ and comparable with the dimensions friends $(r=.45)$ and job $(r=.47)$. It would be interesting to compare the associations between health satisfaction and general life satisfaction between patients and the general population in a more systematic way. Our analyses were controlled for age, education, and tumor stage. Therefore, these factors cannot be considered confounders for the effects. The relevance of the domain income seems to contradict the low importance ratings of this domain. While the patients declare that income is not so relevant for them, those patients who are satisfied with their income report a higher overall QoL than those who are less satisfied with their income. There is no linear relationship between the direct, explicit importance ratings of the dimensions and the indirect assessments based on associations with global QoL. While both analytical approaches reveal the health dimension to be highly relevant, the income dimension shows that the results of these two approaches may differ considerably. A similar phenomenon was observed in a general population study [22] where the domains with highest mean importance ratings were not necessarily those with the highest capability for predicting global life satisfaction. This shows that direct assessments of subjective importance must be considered with caution.

Some limitations of this study should be mentioned. While multiple studies have investigated health-related QoL in urologic cancer patients, assessments of QoL areas beyond health are rare, and considering the subjective importance of other life domains is a relatively new pursuit. Therefore, we could not compare our main findings with results obtained in the scientific literature. The dimension partnership/sexuality included two components which, in the case of urological cancer patients, do not form a consistent scale. We showed that direct importance assessments and indirect

Page 6/13 
assessments in terms of beta coefficients can result in different outcomes. While health was relevant in both approaches, the income dimension showed contradictory results. We cannot derive conclusions about the best way to infer the subjective relevance; a more stringent comparison between these direct and indirect methods would be a task for future research. Though the response rate of this study was relatively good, it is possible that the proportion of patients with severe problems is underrepresented since the 2 sample included only those study participants who had survived until at least three months after $\mathrm{t} 1$ and who were willing and able to take part in the $\mathrm{t} 2$ assessment. Though we tried to select a control group with a similar distribution of age and education, there may be differences with regard to other aspects such as income we could not control for. We addressed several research questions in this paper, but the data set can also be used for testing other relationships, e.g., the correlations between the importance and the satisfaction ratings, or testing the "domain-importance-as-a-leveler-hypothesis" [31] that postulates a moderating effect of the domain importance on the associations between domain satisfaction and global QoL, or the associations between changes in importance (from t1 to t2) and changes in satisfaction.

In summary, the results of this study underline that health is a relevant dimension of QoL but not solely so. The importance of the domain income/finances shows that this aspect is also meaningful for understanding cancer patients' life situation, even if they do not explicitly state that to be the case. The domain partnership/sexuality is especially sensitive for urologic cancer patients and should be taken into account in the cancer care setting. Domain importance is meaningful. Even if importance ratings are not necessary for qualifying a weighted global QoL score, they are useful tools for better understanding what is truly relevant for patients [44].

\section{Declarations}

Funding The study was funded by the German Research Foundation (Grant number HI 1108/5-1).

Conflict of interest The authors declare that they have no conflict of interest.

Ethical approval The study was approved by the Ethics Committee of the University of Leipzig.

Informed consent Informed consent was obtained from all participants.

Availability of data and material Data supporting the findings will be made available on reasonable request.

Code availability Not applicable

Compliance with Ethical Standards All procedures were in accordance with the ethical standards of the national research committee and with the 1964 Helsinki declaration and its later amendments or comparable ethical standards.

\section{References}

1. Culp, M. B., Soerjomataram, I., Efstathiou, J. A., Bray, F., \& Jemal, A. (2020). Recent global patterns in prostate cancer incidence and mortality rates. European Urology, 77(1), 38-52. doi:10.1016/j.eururo.2019.08.005.

2. Angelis, R. de, Sant, M., Coleman, M. P., Francisci, S., Baili, P., Pierannunzio, D., et al. (2014). Cancer survival in Europe 1999-2007 by country and age: Results of EUROCARE-5-a population-based study. Lancet Oncology, 15(1), 23-34. doi:10.1016/S1470-2045(13)70546-1.

3. Volz, Y., Grimm, T., Ormanns, S., Eismann, L., Pfitzinger, P. L., Jokisch, J.-F., et al. (2020). Radical cystectomy for locally advanced urothelial carcinoma of the urinary bladder: Health-related quality of life, oncological outcomes and predictors for survival. Urologic Oncology: Seminars and Original Investigations. doi:10.1016/j.urolonc.2020.10.076.

4. Zhu, A., \& Wittmann, D. (2021). Barriers to sexual recovery in men with prostate, bladder and colorectal cancer. Urologic Oncology, (in press). doi:10.1016/j.urolonc.2020.08.005.

Page 7/13 
5. Lardas, M., Liew, M., van den Bergh, R. C., Santis, M. d., Bellmunt, J., van den Broeck, T., et al. (2017). Quality of life outcomes after primary treatment for clinically localised prostate cancer: A systematic review. European Urology, 72(6), 869-885. doi:10.1016/j.eururo.2017.06.035.

6. Ávila, M., Patel, L., López, S., Cortés-Sanabria, L., Garin, O., Pont, À., et al. (2018). Patient-reported outcomes after treatment for clinically localized prostate cancer: A systematic review and meta-analysis. Cancer Treatment Reviews, 66, 23-44. doi:10.1016/j.ctrv.2018.03.005.

7. Esser, P., Mehnert-Theuerkauf, A., Friedrich, M., Johansen, C., Brähler, E., Faller, H., et al. (2020). Risk and associated factors of depression and anxiety in men with prostate cancer: Results from a German multicenter study. PsychoOncology, 29(10), 1604-1612. doi:10.1002/pon.5471.

8. Hartung, T. J., Moustsen, I. R., Larsen, S. B., Wreford Andersen, E. A., Suppli, N. P., Johansen, C., et al. (2021). Antidepressant prescriptions and associated factors in men with prostate cancer and their female partners. Journal of Cancer Survivorship, in press. doi:10.1007/s11764-020-00947-y.

9. Brunckhorst, O., Hashemi, S., Martin, A., George, G., van Hemelrijck, M., Dasgupta, P., et al. (2020). Depression, anxiety, and suicidality in patients with prostate cancer: A systematic review and meta-analysis of observational studies. Prostate Cancer and Prostatic Diseases, 68, 394. doi:10.1038/s41391-020-00286-0.

10. Zenger, M., Hinz, A., Stolzenburg, J. U., Rabenalt, R., Schwalenberg, T., \& Schwarz, R. (2009). Health-related quality of life of prostate cancer patients compared to the general German population: Age-specific results. Urologia Internationalis, 83(2), 166-170. doi:10.1159/000230018.

11. Hinz, A., Weis, J., Faller, H., Brähler, E., Härter, M., Keller, M., et al. (2018). Quality of life in cancer patients-a comparison of inpatient, outpatient, and rehabilitation settings. Supportive Care in Cancer, 26, 3533-3541. doi:10.1007/s00520-018-4211-4.

12. Kerleau, C., Guizard, A.-V., Daubisse-Marliac, L., Heutte, N., Mercier, M., Grosclaude, P., et al. (2016). Long-term quality of life among localised prostate cancer survivors: QALIPRO population-based study. European Journal of Cancer, 63, 143-153. doi:10.1016/j.ejca.2016.05.020.

13. Adam, S., Doege, D., Koch-Gallenkamp, L., Thong, M. S. Y., Bertram, H., Eberle, A., et al. (2020). Age-specific healthrelated quality of life in disease-free long-term prostate cancer survivors versus male population controls-results from a population-based study. Supportive Care in Cancer, 28(6), 2875-2885. doi:10.1007/s00520-019-05120-5.

14. Namiki, S., Kaiho, Y., Mitsuzuka, K., Saito, H., Yamada, S., Nakagawa, H., et al. (2014). Long-term quality of life after radical prostatectomy: 8-year longitudinal study in Japan. International Journal of Urology, 21(12), 1220-1226. doi:10.1111/iju.12586.

15. Sanda, M. G., Dunn, R. L., Michalski, J., Sandler, H. M., Northouse, L., Hembroff, L., et al. (2008). Quality of life and satisfaction with outcome among prostate-cancer survivors. New England Journal of Medicine, 358(12), 1250-1261. doi:10.1056/NEJMoa074311.

16. Talvitie, A.-M., Ojala, H., Tammela, T., Koivisto, A.-M., \& Pietilä, I. (2019). Factors related to self-rated health and life satisfaction one year after radical prostatectomy for localised prostate cancer: A cross-sectional survey. Scandinavian Journal of Caring Sciences, 33(3), 688-697. doi:10.1111/scs.12664.

17. Sosnowski, R., Kulpa, M., Kosowicz, M., Presicce, F., Porpiglia, F., Tubaro, A., et al. (2017). Basic methods for the assessment of health-related quality of life in uro-oncological patients. Minerva Urologica e Nefrologica = Italian Journal of Urology and Nephrology, 69(5), 409-420. doi:10.23736/S0393-2249.16.02726-0.

18. Russell, L. B., Hubley, A. M., Palepu, A., \& Zumbo, B. D. (2006). Does weighting capture what's important?: Revisiting subjective importance weighting with a quality of life measure. Social Indicators Research, 75(1), 141-167. doi:10.1007/s11205-004-2528-5.

19. Wu, C.-H., \& Yao, G. (2006). Do we need to weight satisfaction scores with importance ratings in measuring quality of life? Social Indicators Research, 78(2), 305-326. doi:10.1007/s11205-005-0212-z. 
20. Hsieh, C.-M. (2012). Should we give up domain importance weighting in QoL measures? Social Indicators Research, 108(1), 99-109. doi:10.1007/s11205-011-9868-8.

21. Henrich, G., \& Herschbach, P. (2000). Questions on Life Satisfaction (FLZ ${ }^{(M)}$ ) - A short questionnaire for assessing subjective quality of life. European Journal of Psychological Assessment, 16(3), 150-159.

22. Rohrer, J. M., \& Schmukle, S. C. (2018). Individual importance weighting of domain satisfaction ratings does not increase validity. Collabra. Psychology, 4(1). doi:10.1525/collabra.116.

23. Daig, I., Herschbach, P., Lehmann, A., Knoll, N., \& Decker, O. (2009). Gender and age differences in domain-specific life satisfaction and the impact of depressive and anxiety symptoms: a general population survey from Germany. Quality of Life Research, 18(6), 669-678.

24. Sehlen, S., Marten-Mittag, B., Herschbach, P., Schweden, M., Book, K., Henrich, G., et al. (2012). Health-related quality of life supersedes other psychosocial predictors of long-term survival in cancer patients undergoing radiotherapy. Acta Oncologica, 51(8), 1020-1028. doi:10.3109/0284186X.2012.683879.

25. Amler, S., Sauerland, M. C., Deiters, C., Büchner, T., \& Schumacher, A. (2015). Factors influencing life satisfaction in acute myeloid leukemia survivors following allogeneic stem cell transplantation: A cross-sectional study. Health and Quality of Life Outcomes, 13, 28. doi:10.1186/s12955-015-0222-8.

26. Leuteritz, K., Friedrich, M., Sender, A., Nowe, E., Stoebel-Richter, Y., \& Geue, K. (2018). Life satisfaction in young adults with cancer and the role of sociodemographic, medical, and psychosocial factors: Results of a longitudinal study. Cancer, 124(22), 4374-4382. doi:10.1002/cncr.31659.

27. Minzlaff, P., Heidt, T., Feucht, M. J., Plath, J. E., Hinterwimmer, S., Imhoff, A. B., et al. (2018). Patient satisfaction with health is substantially improved following ACL reconstruction. Knee Surgery, Sports Traumatology, Arthroscopy, 26(2), 582-588. doi:10.1007/s00167-017-4623-6.

28. Kröger, C., Bode, K., Wunsch, E.-M., Kliem, S., Grocholewski, A., \& Finger, F. (2015). Work-related treatment for major depressive disorder and incapacity to work: Preliminary findings of a controlled, matched study. Journal of Occupational Health Psychology, 20(2), 248-258. doi:10.1037/a0038341.

29. Aaronson, N. K., Ahmedzai, S., Bergman, B., Bullinger, M., Cull, A., Duez, N. J., et al. (1993). The EuropeanOrganization-For-Research-And-Treatment-Of-Cancer QLQ-C30 - A quality-of-life instrument for use in international clinical trials in oncology. Journal of the National Cancer Institute, 85(5), 365-376. doi:10.1093/jnci/85.5.365.

30. Cohen, J. (1988). Statistical power analysis for the behavioral sciences (Vol. 2). Hillsdale, NJ: Erlbaum.

31. Tiefenbach, T., \& Kohlbacher, F. (2015). Individual differences in the relationship between domain satisfaction and happiness: The moderating role of domain importance. Personality and Individual Differences, 86, 82-87. doi:10.1016/j.paid.2015.05.040.

32. Leuteritz, K., Friedrich, M., Sender, A., Richter, D., Mehnert-Theuerkauf, A., Sauter, S., et al. (2021). Return to work and employment situation of young adult cancer survivors: Results from the Adolescent and Young Adult-Leipzig Study. Journal of Adolescent and Young Adult Oncology, in press. doi:10.1089/jayao.2020.0055.

33. Vernooij, R. W. M., Cremers, R. G. H. M., Jansen, H., Somford, D. M., Kiemeney, L. A., van Andel, G., et al. (2020). Urinary incontinence and erectile dysfunction in patients with localized or locally advanced prostate cancer: A nationwide observational study. Urologic Oncology, 38(9), 735.e17-735.e25. doi:10.1016/j.urolonc.2020.05.022.

34. Koehler, N., Gansera, L., Stolzenburg, J.-U., Rebmann, U., Truss, M. C., Roth, S., et al. (2012). Early continence in patients with localized prostate cancer. A comparison between open retropubic (RRPE) and endoscopic extraperitoneal radical prostatectomy (EERPE). Urologic Oncology, 30(6), 798-803. doi:10.1016/j.urolonc.2010.10.013.

35. Chambers, S. K., Ng, S. K., Baade, P., Aitken, J. F., Hyde, M. K., Wittert, G., et al. (2017). Trajectories of quality of life, life satisfaction, and psychological adjustment after prostate cancer. Psycho-Oncology, 26(10), 1576-1585. doi:10.1002/pon.4342. 
36. Parahoo, K., McDonough, S., McCaughan, E., Noyes, J., Semple, C., Halstead, E. J., et al. (2015). Psychosocial interventions for men with prostate cancer: A Cochrane systematic review. BJU International, 116(2), 174-183. doi:10.1111/bju.12989.

37. Park, S., Kim, K., Ahn, H. K., Kim, J. W., Min, G., Chung, B. H., et al. (2020). Impact of lifestyle intervention for patients with prostate cancer. American Journal of Health Behavior, 44(1), 90-99. doi:10.5993/AJHB.44.1.10.

38. Recklitis, C. J., \& Syrjala, K. L. (2017). Provision of integrated psychosocial services for cancer survivors posttreatment. Lancet Oncology, 18(1), e39-e50. doi:10.1016/S1470-2045(16)30659-3.

39. Garos, S., Kluck, A., \& Aronoff, D. (2007). Prostate cancer patients and their partners: Differences in satisfaction indices and psychological variables. Journal of Sexual Medicine, 4(5), 1394-1403. doi:10.1111/j.17436109.2007.00545.x.

40. Schwartz, C. E., Bode, R., Repucci, N., Becker, J., Sprangers, M. A. G., \& Fayers, P. M. (2006). The clinical significance of adaptation to changing health: a meta-analysis of response shift. Quality of Life Research, 15(9), 1533-1550. doi:10.1007/s11136-006-0025-9.

41. Gerlich, C., Schuler, M., Jelitte, M., Neuderth, S., Flentje, M., Graefen, M., et al. (2016). Prostate cancer patients' quality of life assessments across the primary treatment trajectory: 'True' change or response shift? Acta Oncologica, 55(7), 814-820. doi:10.3109/0284186X.2015.1136749.

42. Schwartz, C. E., Quaranto, B. R., Rapkin, B. D., Healy, B. C., Vollmer, T., \& Sprangers, M. A. (2014). Fluctuations in appraisal over time in the context of stable versus non-stable health. Quality of Life Research, 23(1), 9-19.

43. Schwartz, C. E., Sprangers, M. A., Carey, A., \& Reed, G. (2004). Exploring response shift in longitudinal data. Psychology and Health, 19(1), 51-69. doi:10.1080/0887044031000118456.

44. Hsieh, C.-M. (2012). Domain importance is not unimportant: the role of importance wighting in QoL measures. Social Indicators Research, 109(2), 267-278. doi:10.1007/s11205-011-9900-z.

\section{Tables}

Table 1: Sociodemographic and medical characteristics of the sample $(n=173)$ 


\begin{tabular}{|c|c|c|}
\hline & $\mathrm{N}$ & $\%$ \\
\hline Age (Mean, SD) in years & $M=63.0$ & $S D=9.5$ \\
\hline $19-39$ years & 5 & 2.9 \\
\hline 40-59 years & 49 & 28.3 \\
\hline $60-69$ years & 76 & 43.9 \\
\hline$\geq 70$ years & 43 & 24.9 \\
\hline \multicolumn{3}{|l|}{ Relationship status* } \\
\hline Living alone & 20 & 11.6 \\
\hline Living with partner & 152 & 87.9 \\
\hline \multicolumn{3}{|l|}{ Education } \\
\hline$<10$ years & 19 & 11.0 \\
\hline $11-12$ years & 65 & 37.6 \\
\hline$\geq 12$ years & 89 & 51.4 \\
\hline \multicolumn{3}{|l|}{ Tumor site } \\
\hline Penis & 1 & 0.6 \\
\hline Prostate & 150 & 86.7 \\
\hline Testis & 6 & 3.5 \\
\hline Kidney & 7 & 4.0 \\
\hline Bladder & 8 & 4.6 \\
\hline Ureter & 1 & 0.6 \\
\hline \multicolumn{3}{|l|}{ Tumor stage * } \\
\hline 0 & 2 & 1.2 \\
\hline I & 15 & 8.7 \\
\hline II & 110 & 63.6 \\
\hline III & 30 & 17.3 \\
\hline IV & 15 & 8.7 \\
\hline \multicolumn{3}{|l|}{ Time since diagnosis } \\
\hline$<1$ week & 158 & 91.3 \\
\hline 1 week to $<1$ month & 7 & 4.0 \\
\hline$\geq 1$ month & 8 & 4.6 \\
\hline \multicolumn{3}{|l|}{ Medical treatment } \\
\hline Surgery & 162 & 93.6 \\
\hline Chemotherapy & 16 & 9.2 \\
\hline Radiotherapy & 4 & 2.3 \\
\hline
\end{tabular}

Page $11 / 13$ 
Note. *: Missing data not reported; M: Mean; SD: Standard deviation

Table 2. Importance ratings. Mean scores and effect sizes for patients $(n=173)$ and the general population $(n=477)$

\begin{tabular}{|c|c|c|c|c|c|c|c|c|c|c|c|c|}
\hline & \multicolumn{6}{|c|}{ Mean Scores and SDs } & \multicolumn{6}{|c|}{ Differences } \\
\hline & \multirow{2}{*}{\multicolumn{2}{|c|}{ Patients t1 }} & \multirow{2}{*}{\multicolumn{2}{|c|}{ Patients t2 }} & \multirow{2}{*}{\multicolumn{2}{|c|}{ G.P. }} & \multirow{2}{*}{\multicolumn{2}{|c|}{$\begin{array}{l}\text { Patients t1- } \\
\text { G.P. }\end{array}$}} & \multirow{2}{*}{\multicolumn{2}{|c|}{$\begin{array}{l}\text { Patients t2 - } \\
\text { G.P. }\end{array}$}} & \multirow{2}{*}{\multicolumn{2}{|c|}{$\begin{array}{l}\text { Patients t2 - } \\
\text { Patients t1 }\end{array}$}} \\
\hline & & & & & & & & & & & & \\
\hline & $M$ & $(S D)$ & $M$ & (SD) & $M$ & (SD) & $\begin{array}{l}\text { Effect } \\
\text { size } d\end{array}$ & $p$ & $\begin{array}{l}\text { Effect } \\
\text { size } d\end{array}$ & $p$ & $\begin{array}{l}\text { Effect } \\
\text { size } d\end{array}$ & $p$ \\
\hline Friends & 3.76 & $(.82)$ & 3.71 & $(.79)$ & 3.54 & $(.83)$ & 0.27 & .003 & 0.21 & .018 & -0.06 & .390 \\
\hline $\begin{array}{l}\text { Leisure } \\
\text { time }\end{array}$ & 3.71 & $(.85)$ & 3.66 & $(.70)$ & 3.45 & $(.87)$ & 0.30 & $<.001$ & 0.26 & .002 & -0.05 & .449 \\
\hline Health & 4.49 & $(.59)$ & 4.51 & $(.58)$ & 4.58 & $(.60)$ & -0.17 & .060 & -0.12 & .147 & 0.03 & .624 \\
\hline Income & 3.68 & $(.76)$ & 3.79 & $(.81)$ & 4.13 & $(.67)$ & -0.65 & $<.001$ & -0.47 & $<.001$ & 0.14 & .123 \\
\hline Work & 3.70 & $(.87)$ & 3.73 & $(.86)$ & 3.61 & $(1.26)$ & 0.08 & .100 & 0.10 & .171 & 0.05 & .630 \\
\hline Housing & 3.88 & (.78) & 3.84 & $(.87)$ & 3.97 & $(.73)$ & -0.12 & .311 & -0.16 & .100 & -0.04 & .645 \\
\hline Family life & 4.35 & $(.80)$ & 4.24 & (.83) & 4.01 & $(.99)$ & 0.36 & $<.001$ & 0.24 & .006 & -0.13 & .069 \\
\hline Partnership & 3.98 & $(.88)$ & 3.82 & $(.81)$ & 3.76 & $(1.02)$ & 0.22 & .009 & 0.06 & .453 & -0.18 & .018 \\
\hline
\end{tabular}

Note. G.P. General Population; M: Mean; SD: standard deviation. Bold type indicates statistical significance with $p<0.05$.

Table 3. Satisfaction ratings. Mean scores and effect sizes for patients $(n=173)$ and the general population $(n=477)$

\begin{tabular}{|c|c|c|c|c|c|c|c|c|c|c|c|c|}
\hline & \multicolumn{6}{|c|}{ Mean Scores and SDs } & \multicolumn{6}{|c|}{ Differences } \\
\hline & \multirow{2}{*}{\multicolumn{2}{|c|}{ Patients t1 }} & \multirow{2}{*}{\multicolumn{2}{|c|}{ Patients t2 }} & \multirow{2}{*}{\multicolumn{2}{|c|}{ G.P. }} & \multirow{2}{*}{\multicolumn{2}{|c|}{$\begin{array}{l}\text { Patients t1 - } \\
\text { G.P. }\end{array}$}} & \multirow{2}{*}{\multicolumn{2}{|c|}{$\begin{array}{l}\text { Patients t2 - } \\
\text { G.P. }\end{array}$}} & \multirow{2}{*}{\multicolumn{2}{|c|}{$\begin{array}{l}\text { Patients t2 - } \\
\text { Patients t1 }\end{array}$}} \\
\hline & & & & & & & & & & & & \\
\hline & M & $(S D)$ & $\mathrm{M}$ & $(S D)$ & M & (SD) & $\begin{array}{l}\text { Effect } \\
\text { size } d\end{array}$ & $p$ & $\begin{array}{l}\text { Effect } \\
\text { size } d\end{array}$ & $p$ & $\begin{array}{l}\text { Effect } \\
\text { size } d\end{array}$ & $p$ \\
\hline Friends & 4.06 & $(.83)$ & 3.97 & $(.86)$ & 3.86 & $(.76)$ & 0.26 & .004 & 0.13 & .146 & -0.11 & .107 \\
\hline $\begin{array}{l}\text { Leisure } \\
\text { time }\end{array}$ & 3.93 & $(.93)$ & 3.64 & $(.92)$ & 3.77 & $(.81)$ & 0.19 & .031 & -0.16 & .093 & -0.31 & $<.001$ \\
\hline Health & 3.08 & $(1.20)$ & 3.27 & $(1.10)$ & 3.58 & $(.90)$ & -0.50 & $<.001$ & -0.33 & .001 & 0.17 & .022 \\
\hline Income & 3.80 & $(.91)$ & 3.74 & $(.97)$ & 3.66 & $(.84)$ & 0.17 & .055 & 0.09 & .283 & -0.06 & .306 \\
\hline Work & 3.82 & $(.97)$ & 3.58 & $(1.06)$ & 3.59 & $(1.02)$ & 0.23 & .011 & -0.01 & .954 & -0.23 & .001 \\
\hline Housing & 4.38 & $(.77)$ & 4.33 & $(.81)$ & 4.11 & $(.76)$ & 0.35 & $<.001$ & 0.28 & .002 & -0.06 & .273 \\
\hline Family life & 4.30 & $(.96)$ & 4.14 & $(.98)$ & 4.02 & $(.86)$ & 0.31 & $<.001$ & 0.14 & .149 & -0.16 & .012 \\
\hline Partnership & 3.76 & $(1.12)$ & 3.31 & $(1.07)$ & 3.72 & $(1.05)$ & 0.03 & .753 & -0.39 & $<.001$ & -0.41 & $<.001$ \\
\hline
\end{tabular}


Note. G.P. General Population; M: Mean; SD: standard deviation. Bold type indicates statistical significance with $p<0.05$.

Table 4. Results of the regression analyses with global QoL at t2 as the dependent variable

\begin{tabular}{|c|c|c|c|c|c|c|c|c|c|c|c|c|}
\hline & \multirow[t]{2}{*}{ Model } & \multirow[t]{2}{*}{ Adj. $R^{2}$} & \multicolumn{2}{|l|}{ Age } & \multicolumn{2}{|c|}{ Education } & \multicolumn{2}{|l|}{ Stage } & \multicolumn{2}{|c|}{$\begin{array}{l}\text { Domain } \\
\text { baseline }\end{array}$} & \multicolumn{2}{|c|}{$\begin{array}{l}\text { QoL } \\
\text { baseline }\end{array}$} \\
\hline & & & beta & $p$ & beta & $p$ & beta & $p$ & beta & $p$ & beta & $p$ \\
\hline \multirow[t]{2}{*}{ Friends } & M1 & .079 & .170 & .023 & .045 & .520 & -.177 & .019 & .200 & .008 & & \\
\hline & M2 & .199 & .091 & .201 & .056 & .423 & -.145 & .034 & .157 & .025 & .361 & $<.001$ \\
\hline \multirow[t]{2}{*}{ Leisure time } & M1 & .106 & .120 & .109 & .029 & .700 & -.177 & .017 & .260 & .001 & & \\
\hline & M2 & .189 & .072 & .318 & .042 & .552 & -.151 & .033 & .135 & .079 & .328 & $<.001$ \\
\hline \multirow[t]{2}{*}{ Health } & M1 & .206 & .067 & .349 & .081 & .252 & -.173 & .013 & .418 & $<.001$ & & \\
\hline & M2 & .261 & .032 & .642 & .078 & .249 & -.151 & .025 & .323 & $<.001$ & .265 & $<.001$ \\
\hline \multirow[t]{2}{*}{ Income } & M1 & .179 & .062 & .396 & .022 & .758 & -.187 & .009 & .386 & $<.001$ & & \\
\hline & M2 & .260 & .016 & .819 & .034 & .619 & -.158 & .020 & .311 & $<.001$ & .306 & $<.001$ \\
\hline \multirow[t]{2}{*}{ Work } & M1 & .099 & .105 & .171 & .032 & .668 & -.174 & .020 & .252 & .001 & & \\
\hline & M2 & .196 & .055 & .449 & .044 & .536 & -.147 & .037 & .158 & .035 & .337 & $<.001$ \\
\hline \multirow[t]{2}{*}{ Housing } & M1 & .113 & .120 & .106 & .013 & .862 & -.191 & .010 & .276 & $<.001$ & & \\
\hline & M2 & .222 & .054 & .444 & .027 & .693 & -.157 & .024 & .223 & .002 & .346 & $<.001$ \\
\hline \multirow[t]{2}{*}{ Family life } & M1 & .068 & .132 & .086 & .046 & .545 & -.174 & .022 & .172 & .025 & & \\
\hline & M2 & .186 & .066 & .366 & .053 & .453 & -.144 & .043 & .113 & .119 & .362 & $<.001$ \\
\hline \multirow[t]{2}{*}{ Partnership } & M1 & .045 & .156 & .044 & .040 & .598 & -.188 & .014 & .076 & .322 & & \\
\hline & M2 & .175 & .081 & .268 & -.050 & .488 & -.152 & .034 & .035 & .622 & .376 & $<.001$ \\
\hline
\end{tabular}

Note. Domain baseline: $\mathrm{t} 1$ score of the respective domain; M1: Model 1 with the independent variables age, education, stage, and domain baseline; M2: Model 2 with the independent variables of M1 and the 11 score of global QoL; Bold type indicates statistical significance with $p<0.05$. 